\title{
Cervical aortic arch and a new type of double aortic arch Report of a case
}

\author{
Mario Cornali, Enrico Reginato, and Gaetano Azzolina \\ From the Department of Pediatric Cardiothoracic Surgery, Ospedale Generale Provinciale, 54100 Massa, \\ Italy
}

A case of cervical aortic arch is reported. To the best of our knowledge, it is the first to be associated with a serious intracardiac anomaly. In addition, it is part of a new type of double aortic arch, caused by failure of reabsorption of both dorsal aortic roots and persistence of the fourth right and second (or third) left branchial arches.

Cervical aortic arch is a rare anomaly. A review of world publications shows only 17 reported cases (Beavan and Fatti, 1947; Bender, Menges, and Shulze, 1964; Chang et al., 1971; Defrenne and Verney, 1968; De Jong and Klinkhamer, 1969; DuBrow et al., 1974; Gravier, Vialtel, and Pinet, 1959; Harley, 1959; Hastreiter, D'Cruz, and Cantez 1966; Mahoney and Manning, 1964; Massumi, Wiener, and Charif, 1963; Mullins, Gillete, and McNamara, 1973; Pitzus and Camoglio, 1974; Richie et al., 1972; Sheperd, Kerth, and Rosenthal, 1969; Shuford et al., 1972). Right-sided in the majority of instances, it has been found only as an isolated entity. The purpose of this article is to describe a case associated with pseudotruncus and which constitutes a new type of asymptomatic double aortic arch.

\section{Case report}

A 33-month-old undernourished male child,cyanotic since the age of 1 month, with a history of several upper respiratory infections was admitt3d for evaluation. Pertinent physical findings were a systolic thrill over the left supraclavicular region and a superficial venous network over face, neck, and upper trunk. Peripheral pulses were normal. Laboratory studies were within normal limits except for haematocrit $(63 \%)$ and haemoglobin $(17 \cdot 3 \mathrm{~g} / 100 \mathrm{ml})$. Electrocardiogram showed obvious right axis deviation, right atrial overload, pro- nounced right ventricular hypertrophy, and systolic overload. Phonocardiogram showed a modest systolic murmur at the second and third interspaces and an increased second heart sound. On chest $x$-ray film the heart was slightly enlarged; the apex was rounded and tilted upward. The pulmonary artery segment was concave and the hilar and pulmonary vascular markings were decreased. In the left anterior oblique projection the aortic knob was unusually high and prominent. Lungs were clear. At cardiac catheterization very low oxygen saturation values were found both in the venous $(34.8 \%$ in right atrium) and arterial systems (38.9\% in ascending aorta). The pulmonary artery could not be entered. The right ventricular pressure was $85 / 3-5 \mathrm{mmHg}(11 \cdot 3 / 0 \cdot 4-0 \cdot 7 \mathrm{kPa})$.

\section{Cineangiocardiogram}

The right infundibulum wrs atretic. A dilated ascending aorta overrode a large ventricular septal defect. The aortic arch was right-sided. The first aortic branch crossed the midline, ascended to the left side of the neck, then turned abruptly downward and rejoined the aorta at the level of the rightsided arch. The second and third branches were, respectively, the right subclavian and right common carotid arteries. The left brachiocephalic arteries could not be properly assessed, but the left common carotid artery seemed to arise from the descending portion of the left cervical arch. A hypoplastic main pulmonary artery was supplied by a small persistent ductus arteriosus which originated from the 
L.C.C.A.

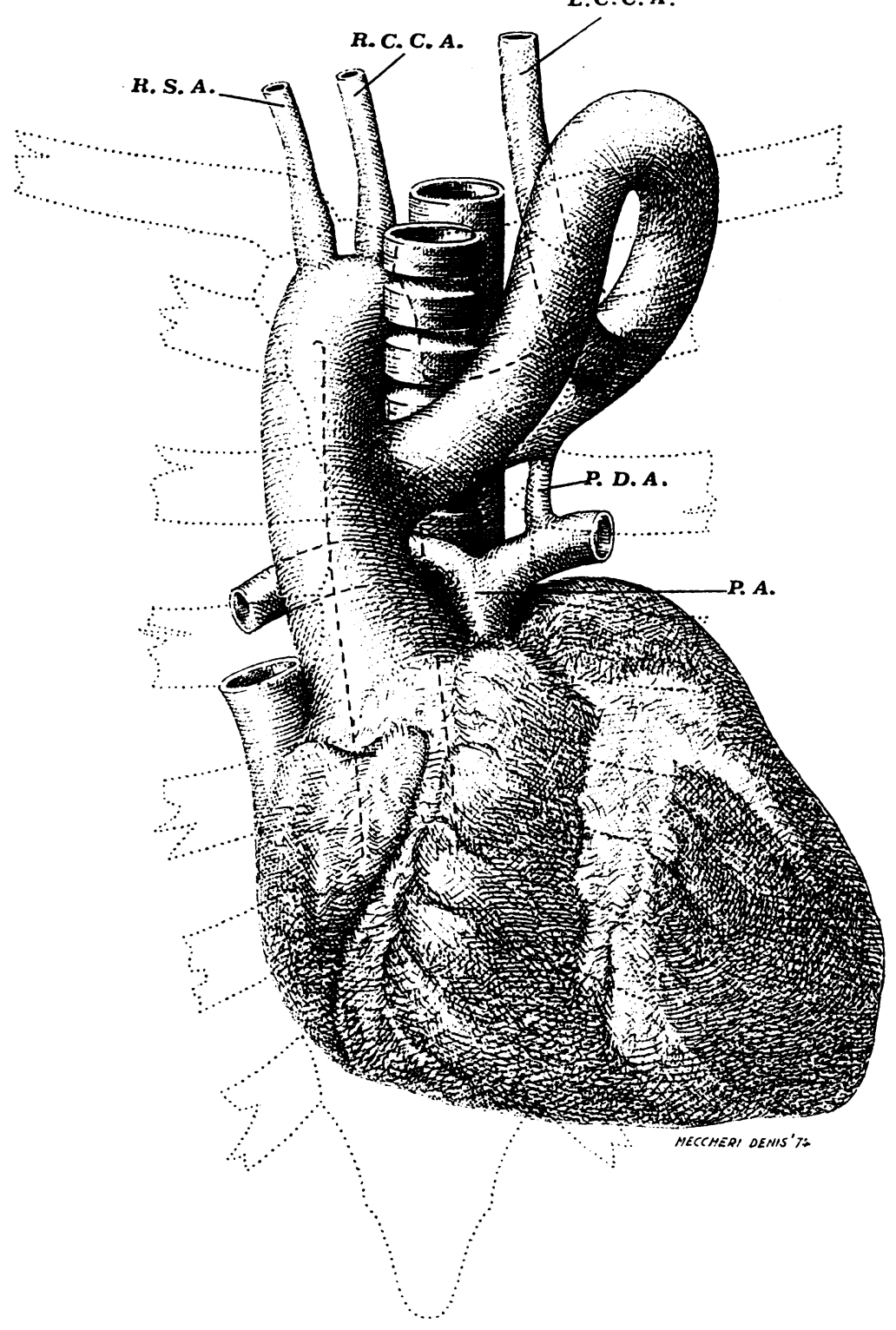

FIG. Artist's representation showing the double aortic arch; left common carotid artery ( $L C C A)$; right common carotid artery ( $R C C A)$; right subclavian artery $(R S A)$; pulmonary artery $(P A)$; persistent ductus arteriosus $(P D A)$. 
posterior portion of the cervical aortic arch. The thoracic aorta descended obliquely to the right of the spine and crossed the midline at the level of the diaphragm. Diagnosis was: pseudotruncus, hypoplastic pulmonary artery and branches supplied by a left persistent ductus arteriosus, right aortic arch, and left cervical aortic arch (Fig.). The child was discharged and no treatment was planned.

\section{Discussion}

Double aortic arch and cervical aortic arch are developmental defects of the primordial branchial arches.

\section{Double aortic arch}

As a rule, the double aortic arch results from persistence of both right and left fourth branchial arches. Usually the arches are at the same level, the right one being, at most, slightly higher. In our case the arches are at different levels. According to Edward's hypothetical double aortic arch (Stewart, Kinkaid, and Edwards, 1964), the malformation can be explained by failure of reabsorption of both dorsal aortic roots and persistence of the fourth right and second (or third) left branchial arches. The vascular ring results from the following structures: on the right, the ascending aorta proper and the right arch; anteriorly, the ascending portion of the cervical arch; on the left and posteriorly, the left cervical arch connecting with the right-sided thoracic aorta. The small persistent ductus arteriosus has no bearing in the formation of the ring.

Double aortic arch is usually suspected because of symptoms related to compression upon trachea and/or oesophagus. Our case had no symptoms because the ring was not encroaching upon these structures. In the majority of cases the diagnosis is easily made with angiography.

\section{Cervical aortic arch}

The origin of cervical aortic arch is still controversial. One theory (Lewis and Rogers, 1953) holds that it is caused by retention of the fourth branchial arch at the cervical level. According to another theory (Beavan and Fatti, 1947; Harley, 1959; Lewis and Rogers, 1953; Mahoney and Manning, 1964) it derives directly from the third or second branchial arch. The controversy has been extensively explored by Shuford et al. (1972), who have shown that both hypotheses are equally valid. The first theory cannot explain the coexistence of a right thoracic arch with a left cervical arch in our case. One would have to assume a normal descent of the fourth arch on the right and a retention in the cervical region of the same arch on the left. A differential origin of the two arches, the right from the fourth and the left from the third (or second arch) is more likely.

The cervical aortic arch is usually asymptomatic, but symptoms related to compression of vital structures, such as stridor, dyspnoea, dysphagia, and frequent upper respiratory infections can be encountered. In a patient with a pulsating cervical mass the correct diagnosis can be suspected clinically and further substantiated by the disappearance of femoral pulses upon compression of the mass. A chest film may show a prominence or an abnormal knob on the left (or right) superior mediastinum. A mediastinal widening can be the only radiological finding. In some cases, however, the trachea is slightly displaced and compressed; in others, a barium study might show a posterolateral filling defect in the oesophagus, very similar to that occurring with an aberrant subclavian artery. Radiologically the differential diagnosis includes aortic diverticulum, aneurysmal dilatation of the aortic arch and/or branches, neurinoma, goitre, pulsion oesophageal diverticulum, buckling of the innominate artery, upper lobe atelectasis, dilatation of the superior vena cava, and aberrant right subclavian artery. Only angiography makes diagnosis possible. The contrast medium should be injected into the left ventricle or above the aortic valve. The ascending aorta, elongated and usually of normal size, reaches the supraclavicular region whence it turns abruptly downward. The aortic branches may be irregular in their distribution, but follow a well-defined embryological pattern. The descending aorta crosses the midline if the thoracic aorta is controlateral to the cervical arch.

Typically, the overall appearance has been compared to a hair-pin loop (Shuford et al., 1972).

We wish to express our gratitude to Dr. Sergio Eufrate for critically reviewing the article.

\section{References}

Beavan, T. E. D., and Fatti, L. (1947). Ligature of aortic arch in the neck. British fournal of Surgery, 34, 414.

Bender, F., Menges, G., and Shulze, W. (1964). Seltene Verlaufsanomalie des Aortenbogens mit rechtshorakaler Schleifenbildung. Fortschritteaug dem Gebute der Roentgenstrahlen, 100, 203.

Chang, L. W. M., Kaplan, E. L., Baum, D., and Figley, M. M. (1971). Aortic arch in the neck: a case report. Fournal of Pediatrics, 79, 788.

D'Cruz, I. A., Cantez, T., Namin, E. P., Licata, R., and Hastreiter, A. R. (1966). Right-sided aorta. Part II: Right aortic arch, right descending aorta, and associated anomalies. British Heart fournal, 28, 725.

Defrenne, P., and Verney, R. (1968). L'aorte cervicale. Annales de Radiologie, 11, 525. 
De Jong, I. H., and Klinkhamer, A. C. (1969). Left-sided cervical aortic arch. American fournal of Cardiology, 23, 285.

DuBrow, I. W., Burman, S. O., Elias, D. O., Hastreiter, A. R., and Pietras, R. J. (1974). Aortic arch in the neck. fournal of Thoracic and Cardiovascular Surgery, 68, 21.

Gravier, G., Vialtel, M., and Pinet, F. (1959). A propos d'une tumeur pulsatile du cou: un cas d'aorte cervicale. Pédiatrie, 14, 437.

Harley, H. R. S. (1959). The development and anomalies of the aortic arch and its branches with the report of a case of right cervical aortic arch and intrathoracic vascular ring. British fournal of Surgery, 46, 561.

Hastreiter, A. R., D'Cruz, I. A., and Cantez, T. (1966). Right-sided aorta. Part I: Occurrence of right aortic arch in various types of congenital heart disease. British Heart fournal, 28, 722.

Lewis, C., and Rogers, L. (1953). The cervical aortic knuckle which resembles an aneurysm. Lancet, 1, 825.

Mahoney, E. B., and Manning, J. A. (1964). Congenital abnormalities of the aortic arch. Surgery, $55,1$.

Massumi, R., Wiener, L., and Charif, P. (1963). The syndrome of cervical aorta. Report of a case and review of the previous cases. American fournal of Cardiology, 11, 678.
Mullins, C. E., Gillette, P. C., and McNamara, D. G. (1973). The complex of cervical aortic arch. Pediatrics, 51, 210.

Pitzus, E., and Camoglio, E. (1974). La sindrome dell'aorta cervicale. A proposito di un caso clinico. Giornale Italiano di Cardiologia, 4, 217.

Richie, R., Del Rio, C., Mullins, C. E., and Hall, R. J. (1972). Right-sided cervical aortic arch. American Heart fournal, 84, 531.

Sheperd, R. M., Kerth, W. J., and Rosenthal, J. H. (1969). Right cervical aortic arch with left descending aorta. Case report and review of the literature. American fournal of Diseases of Children, 118, 642.

Shuford, W. H., Sybers, R. G., Milledge, R. D., and Brinsfield, D. (1972). The cervical aortic arch. American Fournal of Roentgenology, Radium Therapy and Nuclear Medicine, 116, 519.

Stewart, J. R., Kinkaid, O. W., and Edwards, J. E. (1964). An Atlas of Vascular Rings and Related Malformations of the Aortic Arch System. Thomas, Springfield, Illinois.

Requests for reprints to Dr. Mario Cornali, Ospedale Generale Provinciale, 54100 Massa, Italy. 